УДК 811.112.2' 367.623: 81'373.611: 81'37

DOI: $10.24144 / 2617-3921.2020 .18 .72-80$

Myroslava Ladtschenko Dozentin Doktor des Lehrstuhls für deutsche Philologie der Nationaluniversität Uschhorod orcid.org/0000-0002-4007-5467

Uschhorod, Ukraine, + 38(050) 2309444 miroslava.ladchenko@uzhnu.edu.ua

\title{
Wortbildende und semantische Besonderheiten der deutschen Adjektive mit Halbpräfixen
}

Анотація. Одним із способів німецького словотворення є утворення похідних слів за допомогою напівафіксів. Словотворення із напівафіксами належить до однієї із найбільш дискусійних проблем у німецькій лінгвістиці. За допомогою напівафіксів утворюються іменники та прикметники. Напівафікси - ие особливий тип афіксів, утворених від певних слів, які втратила своє самостійне лексичне значення. Напівафікси позначаються також терміном «афіксоїди», які є синонімами. Відповідно розрізняють напівпрефікси або префіксоїди та напівсуфікси або суфріксоїди. Саме тому утворення із напівафіксами відносять переважно не до складних, а до похідних слів. Однак деякі мовознавиі відносять иі утворення до складних слів. Напівпрефікси утворилися із самостійних слів, які мають ознаку стати префріксами. Приєднуючись до іменникових або прикметникових основ, вони частково втрачають свою семантику, набуваючи при иьому узагальнююче значення. Більшість досліджених прикметників креативні та експресивні, їм притаманні перенесені значення. Цілий ряд лексем мають емоційнопідсилюючий зміст, тому ї вживання відзначається певними особливостями. У більшості випадків підсилюються позитивні значення прикметників. Напівпрефікси мають також негативну семантику, що зустрічається переважно у розмовній мові. Більшість прикметників вживаються тільки в розмовній мові. Прикметники літературної німецької мови, окрім основного значення, у розмовній німецькій мові мають перенесені значення.

Ключові слова: словниковий склад, похідні слова, складні слова, гібридні утворення, генетичний аналіз, розмовна мова, емочійне значення.

Abstract. The formation of derivatives with the help of semi-affixes is one of the productive ways of German word-formation. Word-formation with semi-affixes is one of the most controversial issues in German linguistics. Nouns and adjectives are formed with the help of semi-affixes. Semi-affixes present a special type of affixes formed from certain words that have lost their independent lexical meaning. They are also referred to as "affixoids", a synonymous term. Accordingly, semi-prefixes 
or prefixoids and semi-suffixes or suffixoids are further distinguished. Therefore, derivatives with semi-affixes are mainly regarded as derived words, not complex. However, some linguists refer to these formations as complex words. Semi-prefixes are formed from independent words that may become prefixes. By joining noun or adjective bases, they partially lose their semantics, while acquiring a generalizing meaning. Most of the studied adjectives are creative and expressive, with transferred meanings. A number of lexical units have an emotionally reinforcing meaning, so their use is marked by certain features. In most cases, the positive meanings of adjectives are amplified. There are cases when semi-prefixes have negative semantics, which occurs mainly in colloquial language. Most adjectives are used only in colloquial language. Adjectives of literary German, in addition to the main meaning, in spoken German acquire transferred meanings.

Keywords: vocabulary, derivatives, complex words, hybrid formations, genetic analyses, colloquial speech, emotional meaning.

Einleitung. Der Wortschatz der deutschen Sprache entwickelt sich ständig. Im Prozess der Wortschatzbereicherung spielt die Wortbildung die größte Rolle. Eines der wichtigsten Probleme ist die Wortbildung mittels der sogenannten Halbaffixe. Mithilfe der Halbsuffixe und Halbpräfixe können sowohl Substantive als auch Adjektive gebildet werden. Besonders produktiv ist diese Wortbildung in der deutschen Umgangssprache, weil Substantive und Adjektive Expressivität und Kreativität besitzen, die gerade für Umgangslexik kennzeichnend sind.

Dieses Problem ist in der deutschen Wortbildung noch nicht ganz gelöst, weil die Sprachforscher verschiedene Meinungen dazu äußern. Einige betrachten die mit bestimmten Affixen gebildeten Lexeme als Ableitungen und die anderen hingegen als Zusammensetzungen. Der vorliegende Artikel betrifft die mit den Halbpräfixen gebildeten Adjektive.

Die Aktualität des Forschungsthemas basiert darauf, dass die Wortbildung und der Gebrauch der Adjektive mit Halbpräfixen bestimmte lexikalische, wortbildende und semantische Besonderheiten aufweisen, die noch nicht vollständig erforscht sind. Dazu gehört es auch die Tatsache, dass mittels der Halbpräfixe immer neue Lexeme gebildet werden, weil gerade die Wortbildung der produktivste Bereicherungsweg des deutschen Wortschatzes ist. Manche von ihnen sind in der Umgangssprache und im Jugendjargon sehr gebräuchlich, weil die mit den Halbpräfixen gebildeten Lexeme expressive Bedeutungsschattierungen haben. Die Neuigkeit der vorliegenden Erforschung besteht darin, dass es hier die Wechselbeziehungen der Wortbildungsprozesse im Bereich der deutschen Adjektive am konkreten Sprachmaterial entdeckt und analysiert werden. In der modernen Sprachwissenschaft kann man wenige Publikationen finden, in denen das Problem der Halbaffixe, darunter auch der Halbpräfixe behandelt werden. Es sei auch zu betonen, dass diese Erforschung einen Teil des von der Autorin erforschten Themas darstellt. 
Viele Sprachforscher sind der Meinung, dass die Ableitungen und Zusammensetzungen genetisch miteinander sehr eng verbunden sind. „Der Prozess der Herausbildung von neuen Affixen vollzieht sich in der Sprache ständig, auch jetzt. In manchen Fällen ist es darum schwer zu unterscheiden, ob wir mit einem Kompositum oder einem Derivat zu tun haben" [5, S. 63]. Die zweiten Komponenten vieler Bildungen haben ihre Bedeutung und ihren selbständigen Gebrauch noch nicht verloren, aber sie zeigen schon einige Merkmale der wortbildenden Suffixe. Man weist auf die Ursachen dieses Prozesses hin [5, S. 63]:

- Sie treten mit vielen Wortstämmen in Verbindung.

- Sie erhielten auch eine neue allgemeine Bedeutung.

M.D. Stepanowa und I.I. Černyševa bezeichnen solche Sprachelemente mit dem Terminus "Halbaffixe": "Das vielumstrittene Problem der "Halbaffixe", das bis jetzt noch keine eindeutige Lösung erhalten hat, bleibt eines der interessantesten und wichtigsten Probleme der deutschen Wortbildung, denn es betrifft solche sprachlichen Faktoren, die man weder leugnen noch umgehen kann. Es handelt sich um das Vorhandensein von Kompositionsgliedern der Komposita, die nicht vereinzelt, sondern serienweise gebraucht werden, und somit die Funktion der Wortbildungsmittel erfüllen, ohne dabei ihre lautliche wie auch partielle semantische Verbindung mit den ihnen entsprechenden Lexemen zu verlieren" [7, S. 115]. Diese Sprachforscherinnen nennen solche Kriterien zur Unterscheidung der Halbaffixe [7, S. 116-117]:

1. der völlige Zusammenfall des Halbaffixes mit dem jeweiligen frei funktionierenden Wort;

2. die etymologische Verbindung des Halbaffixes mit gegebenem Wort;

3. sein häufiger Gebrauch;

4. seine semantische Ähnlichkeit mit gegebenem Wort bei jeweiliger Bedeutungstransformation.

Die Halbaffixe sind also eine besondere Art der Affixe, die aus zusammengesetzten Wörtern gebildet sind. Die erste oder zweite Komponente haben ihre selbstständige lexikalische Bedeutung zum Teil verloren. In diesem Fall erfüllen sie die gleiche Funktion wie die Affixe. Solche Wörter werden Halbsuffixe und Halbpräfixe oder Halbaffixe genannt.

Es gibt keine einheitliche Meinung über die Halbaffixe. Sie werden auch mit dem Terminus Affixoide bezeichnet. Halbaffixe und Affixoide sind Synonyme. Dementsprechend unterscheidet man Halbpräfixe oder Präfixoide und Halbsuffixe oder Suffixoide [1, S. 529]. Die Halbaffixe werden an substantivische und adjektivische Stämme angeschlossen. Den Terminus "Halbaffixe" gebrauchen fast alle deutschen Grammatiker, vor allem die Autoren der Duden-Grammatik [1;3;4].

In der letzten Zeit erscheinen zahlreiche Publikationen der ukrainischen Germanisten, in denen die Probleme der deutschen Wortbildung darunter auch Ableitungen mit Halbaffixen behandelt werden. N. H. Chodakivska untersucht in ihren wissenschaftlichen Artikeln stilistisch markierte abgeleitete Substantive der deutschen Sprache, darunter auch Substantive mit Halbaffixen [15]. V. Kulchitsky 
erforscht in seinen Publikationen deutsche Ableitungen anhand der semantischen Kategorien und schenkt viel Aufmerksamkeit der Semantik der Bildungen mit Halbaffixen [10, S. 25-26]. Der Erforschung der deutschen Halbaffixen sind die Publikationen der Autorin der vorliegenden Abhandlung gewidmet $[6 ; 11 ; 12]$.

Material und Untersuchungsmethoden. Das Forschungsobjekt ist die deutsche Wortbildung. Der Gegenstand der Erforschung sind die deutschen Adjektive aus den Wörterbüchern [2; 9; 13]. Das Ziel der Arbeit ist es, wortbildende, genetische und semantische Besonderheiten der deutschen Adjektive mit Halbpräfixen zu erforschen und zu beschreiben. Bei der Untersuchung des Stoffes wurden solche Verfahren der wissenschaftlichen Forschung wie die Methoden des Recherchierens, Bearbeitens und der Analyse des Stoffes wie auch statistische Angaben verwendet. Ergebnisse und Diskussion. Halbpräfixe stammen aus selbstständigen Wörtern. Sie werden an substantivische oder adjektivische Stämme angeschlossen. Dabei verlieren sie teilweise ihre Semantik und bekommen verallgemeinernde Bedeutung. B. Hinka nennt solche Halbpräfixe der Substantive und Adjektive: blitz-, blut-, bombe-, affe-, bären-, mist-, sau-, stink-, ober- [5, S. 63]. Im „Lexikon der Sprachwissenschaft" von H. Bußmann werden die nächsten Halbpräfixe der Substantive und der Adjektive genannt: Affen-, Mords-, Riesen-; stink-, tod- [1, S. 53]. In der Grammatik „Wahrig“ unterscheidet man viel mehr Halbpräfixe der Substantive und Adjektive: blut-, brand-, erz-, extra-, hoch-, hyper-, kreuz-, pseudo, quasi-, schein-, schei $\beta$-, semi-, stock-, super-, tod-, ultra-, ur-, voll- [8, S. 374]. M. D. Stepanova und I. I. Černyševa nennen folgende Halbpräfixe der Substantive und Adjektive: riese(n)-, mord(s)-, blitz-, grund-, stock-, hoch- (höchst-), über-, all,(allzu-, aller-), stink- (mit verstärkter Bedeutung); ab-, vor-, neben- (mit lokaler Bedeutung, auch in übertragener Bedeutung); ober- (mit der Bedeutung des höheren Grades) [7, S. 374].

In der vorliegenden Erforschung werden nicht alle von den oben angeführten Halbpräfixen unterschieden, weil einige davon als selbstständige Lexeme nicht fungieren. Das betrifft insbesondere Präpositionen, die zu den Dienstwortarten gehören und unserer Meinung nach die Funktion der Halbpräfixe nicht erfüllen können. Den Untersuchungsstoff stellen 245 Adjektive mit 33 Halbpräfixen dar, die aus den genannten Wörterbüchern recherchiert worden sind.

In den linguistischen Quellen gibt es die Methode der Komponentenanalyse für die Bestimmung der Bedeutung sowohl der lexikalischen Einheit als auch ihrer Bestandteile. In diesem Fall wird die Ableitung als eine komplexe Spracheinheit betrachtet, die der folgenden Formel entspricht: $\mathrm{HP}+\mathrm{DB}=\mathrm{AB}, \mathrm{HP}-$ Halbpräfix, DB - Derivationsbasis, AB - Ableitung [14, S. 3]. Dementsprechend werden die Komponenten der abgeleiteten Adjektive genetisch und morphologisch analysiert.

Infolge der genetischen Analyse hat es sich herausgestellt, dass die Halbpräfixe sowohl deutsche als auch fremde Abstammung haben. Die Mehrheit der Halbpräfixe sind deutscher Herkunft. Das sind die nächsten 26 Halbpräfixe, in Klammern ist die Zahl der abgeleiteten Adjektive angegeben: affe(n)- (7), arsch(3), bär(en)- (2), bitter- (7), blitz- (8), blut- (5), bock- (3), brand- (6), dick- (4), 
grund- (10), hase(n)- (2), hoch- (25), hund(e)/hund(s)- (8), knall- (8), mord(s)- (9), ober- (6), pudel- (3), riese- (2), sau-(12), schein- (4), scheiß- (7), schwein(e)- (3), stein- (5), stink- (11), stock- (18), tod- (13). Eine charakteristische Besonderheit der angeführten Halbpräfixe ist, dass sie meistens von den entsprechenden Substantiven gebildet sind. Nur einige von ihnen kommen von den Adjektiven: bitter- (7), dick(4), hoch- (25), ober- (6).

Wenige Halbpräfixe sind fremder Herkunft, gesamt sind es sieben: bombe(n)(4), extra-(5), kreuz- (10), quasi- (3), super- (16), top- (11), ultra- (5). Hier beobachtet man entgegengesetzte Tendenz. Zwei Halbpräfixe kommen von Substantiven griechischer (bombe (n)-), lateinischer (kreuz-) Herkunft, drei stammen von Adverbien lateinischer Herkunft (quasi-, extra-, ultra-) und zwei - von undeklinierbaren Adjektiven lateinischer (super-) und englischer (top-) Herkunft. Die morphologische Analyse der abgeleiteten Adjektive sind in der Tabelle 1 dargestellt.

Tabelle 1

Morphologische Analyse der Halbpräfixe

\begin{tabular}{|c|c|c|c|c|c|}
\hline \multirow[t]{2}{*}{$\begin{array}{c}\text { Morph. } \\
\text { Abstammung } \\
\text { der Halbpräfixe }\end{array}$} & \multicolumn{2}{|c|}{$\begin{array}{c}\text { Anzahl } \\
\text { der Halbpräfixe }\end{array}$} & \multicolumn{2}{|c|}{$\begin{array}{l}\text { Anzahl der } \\
\text { abgeleiteten } \\
\text { Adjektive }\end{array}$} & \multirow{2}{*}{$\begin{array}{l}\text { Beispiele der abgeleiteten } \\
\text { Adjektive mit Halbpräfixen }\end{array}$} \\
\hline & absolute & relative & absolute & relative & \\
\hline Substantiv & 24 & 72,7 & 163 & 66,5 & $\begin{array}{l}\text { blutsauer, brandnotwendig, } \\
\text { grundschlecht, knallhart, } \\
\text { kreuzgefährlich, mordsreich } \\
\text { scheißfreundlich, steinmüde, } \\
\text { stinkreich, stockfremd }\end{array}$ \\
\hline Adjektiv & 6 & 18,2 & 69 & 28,2 & $\begin{array}{l}\text { bitterschwer, dickköpfig, } \\
\text { hochaktuell, hochvornehm, } \\
\text { oberfaul, superbequem, } \\
\text { superneu, topmodern, } \\
\text { topneu }\end{array}$ \\
\hline Adverb & 3 & 9,1 & 13 & 5,3 & \begin{tabular}{|l} 
extraordinär, extrastark, \\
quasilegal, quasioffiziell, \\
ultracool, ultrastark
\end{tabular} \\
\hline gesamt & 33 & $100 \%$ & 245 & $100 \%$ & \\
\hline
\end{tabular}

Die mit den genannten Halbpräfixen gebildeten Adjektive sind in den meisten Fällen Hybridbildungen, die deutsche Derivationsbasis haben. Man kann einige Beispiele anführen: bombenfest, bombensicher, extragroß, extrastark, kreuzdumm, kreuzlangweilig, superbequem, superreich, topmüde, topneu, ultraknackig, ultrastark. Es gibt hybride Ableitungen mit diesen fremden Präfixen, deren Derivationsbasis aus anderen fremden Sprachen kommen, wie z.B.: extradry (lat.+engl.), quasiautomatisch (lat.+ griech.), topaktuell (engl.+lat.), topamüsant 
(engl.+frz.), topinteressant (engl.+lat.), topmodern (engl.+lat.), ultrabombig (lat.+griech.), ultracool (lat.+engl.). Bei einigen abgeleiteten Adjektiven sind die beiden Komponenten aus einer Fremdsprache entlehnt. Meistens ist es lateinische Sprache: extraordinär (lat.+engl.), kreuzfidel (lat.+lat.), quasilegal (lat.+lat.), quasioffiziell (lat.+lat.), superfein (lat.+lat.), supermodern (lat.+lat.), ultramodern (lat.+lat.).

Tabelle 2

\section{Genetische Analyse der abgeleiteten Adjektive}

\begin{tabular}{|l|c|c|l|}
\hline $\begin{array}{c}\text { Genetische Analyse der } \\
\text { Komponenten der } \\
\text { Adjektive }\end{array}$ & $\begin{array}{c}\text { Absolute } \\
\text { Anzahl }\end{array}$ & $\begin{array}{c}\text { Relative } \\
\text { Anzahl }\end{array}$ & $\begin{array}{c}\text { Beispiele der abgeleiteten } \\
\text { Adjektive }\end{array}$ \\
\hline $\begin{array}{l}\text { Deutsches HP + } \\
\text { deutsche DB }\end{array}$ & 161 & 65,7 & $\begin{array}{l}\text { arschkalt, blitzböse, mordskalt } \\
\text { oberfaul, riesenstark, saugut, } \\
\text { scheißfreundlich, steinhart, } \\
\text { stinkeinsam, stockfremd }\end{array}$ \\
\hline $\begin{array}{l}\text { Deutsches HP + fremde } \\
\text { DB }\end{array}$ & 30 & 12,2 & $\begin{array}{l}\text { hochfein, hundsmiserabel, } \\
\text { mordsfidel, scheißegal }\end{array}$ \\
\hline $\begin{array}{l}\text { fremdes HP + deutsche } \\
\text { DB }\end{array}$ & 32 & 13,1 & $\begin{array}{l}\text { extrastark, kreuzgefährlich, } \\
\text { bombensicher, superleicht, } \\
\text { topmüde, ultrastark }\end{array}$ \\
\hline $\begin{array}{l}\text { fremdes HP + fremde } \\
\text { DB }\end{array}$ & 22 & 9,0 & $\begin{array}{l}\text { quasioffiziell, supermodern, } \\
\text { topamüsant, ultracool }\end{array}$ \\
\hline gesamt & 245 & $100 \%$ & \\
\hline
\end{tabular}

Die überwiegende Mehrheit der Adjektive wird umgangssprachlich verwendet. Das sind vor allem Adjektive, die auf kreative Weise gebildet sind. Diese Lexik besitzt Expressivität und Kreativität. Das geschieht infolge der Sinnveränderungen der Adjektive. Die meisten Halbpräfixe dienen zur emotionellen Verstärkung der Semantik der abgeleiteten Adjektive. Im Duden-Wörterbuch steht es bei diesen Adjektiven „emotional verstärkend“. Diese Verstärkung hat inhaltlich fast immer die gleiche Erklärung, obwohl sie wörtlich unterschiedlich sein kann: sehr, äußerst, besonders, ganz, ganz und gar, absolut, völlig, in hohem Maße, höchst, überaus, außerordentlich. Viele Halbpräfixe verstärken die Bedeutung der positiven Eigenschaften und Merkmale der abgeleiteten Adjektive. Als Beispiele kann man die Ableitungen mit einigen Halbpräfixen nennen: hoch-: hochfein - sehr fein, erstklassig, hochvornehm - sehr vornehm, hochzufrieden - sehr zufrieden; bomben-: bombenfest/ bombensicher - unverrückbar fest; bombenruhig - sehr ruhig; grund-: grundgescheit - sehr klug, grundgütig - absolut anständig, kreuz-: kreuzanständig, - sehr anständig, kreuzehrlich - sehr ehrlich, kreuzfidel - sehr vergnügt, tod-: todehrlich - sehr ehrlich, todrichtig - äußerst richtig, todschick außerordentlich schick. 
Es gibt acht Halbpräfixe, die von den Tiernamen stammen: affe(n)-, bär(en)-, bock-, hase(n)-, hund(e)/hund(s), pudel-, sau-, schwein(e)-. Außer der verstärkenden Funktion besitzen sie oft abwertende Bedeutungen, weil die Tiere mit bestimmten Begriffen assoziiert werden: Ärger, Kraft, Hunger, Angst usw. In den meisten Fällen sind es negative Merkmale und Eigenschaften sowohl der Menschen als auch der Gegenstände und Erscheinungen. Zum Beispiel: hundserbärmlich - unerträglich schlecht, hundsgemein - höchst unfein, hundsmiserabel - überaus schlecht, saufrech - sehr frech, sauschlecht - sehr schlecht, schweinekalt - sehr kalt, schweinemäßig sehr schlecht, miserabel, schweineteuer - ungemein teuer.

Außer der Verstärkung, Vergrößerung beinhalten einige Halbpräfixe grobe, derbe, abwertende Bedeutungen. Das sind zwei Halbpräfixe arsch-: und schei $\beta$-. Die abgeleiteten Adjektive drücken den höchsten Grad der pejorativen Emotionalität aus. Zum Beispiel: arschkahl - sehr kahl, arschkalt - sehr kalt, arschklar - sehr klar; scheißfaul - sehr faul, scheißfein - sehr fein, scheißfreundlich - sehr freundlich, scheißhöflich - sehr höflich, scheißkalt - sehr kalt, scheißklug - überaus klug.

Man kann die häufigsten positiven und negativen Merkmale und Eigenschaften der mit den Halbpräfixen gebildeten Adjektive gruppieren. Positive Semantik besitzen zum Beispiel folgende abgeleitete Adjektive: affenstark, bärenstark, bitterernst, blitzgescheit, bockstark, bombenruhig, bombensicher, extrastark, grundbrav, grundehrlich, grundgescheit, grundgütig, grundrichtig, hochbegabt, hochelegant, hochfein, hochgeistig, hochherzig, hochklassig, hochvornehm, kreuzanständig, kreuzbrav, kreuzehrlich, riesenstark, stinkvornehm, superschlank, superstark, todehrlich, todernst, todrichtig, todschick, topamüsant, topfit, topmodern, topmodern, ultramodern, ultrastark. Sie drücken die nächsten Eigenschaften und Merkmale aus:

Anständigkeit, Begabung, Ehrlichkeit, Ernst, Klugheit, Ruhe, Richtigkeit, Schönheit, Sicherheit, Stärke.

Zur zweiten Gruppe gehören die Adjektive mit negativer Semantik: affenmäßig, affenrund, bitterböse, blitzböse, blitzdumm, blutrünstig, blutsauer, dickfellig dickköpfig, dickschädlig, grundschlecht, hochgiftig, hochnäsig, hundemäßig, hundsgemein, kreuzdumm, kreuzlangweilig, mordsdämlich, mordsdumm, mordsmäßig, oberdoof, oberfaul, obermies, oberschlau, scheinheilig, stinkfaul, stinklangweilig, stinksauer, stockdumm, stocksauer, todlangweilig. Sie drücken Bosheit, Dummheit, Eigensinnigkeit, Falschheit, Faulheit, Gleichgültigkeit, Langweile, Schlechtigkeit aus.

Schlussfolgerungen und Forschungsperspektiven. Zusammenfassend lässt es sich schlussfolgern, dass die Wortbildung mittels der Halbaffixe eines der wichtigsten Probleme der Bereicherung des deutschen Wortschatzes ist. Das betrifft auch das in der vorliegenden Abhandlung erforschten Problems der Adjektive mit Halbpräfixen. Die Halbpräfixe stammen aus selbstständigen Wörtern, die ihre Hauptbedeutung zum Teil verloren haben. Infolgedessen wurden sie zu den Präfixen und dienen zur emotionellen Verstärkung der Bedeutungen der Adjektive. Die produktivsten Halbsuffixe bei der Bildung der Adjektive sind: kreuz-, sau-, stink-, 
stock-, tod-. Alle Adjektive mit den Halbpräfixen gehören zu den Ableitungen. Die Wortbildung der Adjektive mit den erforschten Halbpräfixen ist sehr unterschiedlich und interessant. Sie ist durch Kreativität und Expressivität kennzeichnend. Die meisten Halbpräfixe sind deutscher Herkunft. Es gibt auch Halbpräfixe fremder Abstammung. Der Wortbildungsprozess der Adjektive mit Halbpräfixen hat bestimmte lexikalische, wortbildende und semantische Besonderheiten. Zur weiteren Forschungsperspektiven des gegebenen Themas gehören Substantive mit Halbaffixen so wie Adjektive mit Halbsuffixen. Es wäre auch zweckmäßig, Wortbildungsprozess mit Halbaffixen im Jugendjargon zu verfolgen.

\section{LITERATUR}

1. Bußmann H. Lexikon der Sprachwissenschaft. Stuttgart: Alfred Kröner Verlag, 2002. $783 \mathrm{~S}$.

2. Duden. Deutsches Universalwörterbuch. Mannheim: Dudenverlag, 2015. 2112 S.

3. Duden. Grammatik der deutschen Gegenwartsprache. Mannheim, Wien, Zürich : Dudenverlag, 1995. - 864 S.

4. Duden. Deutsche Grammatik. Mannheim, Wien, Zürich : Dudenverlag, 1997.- 409 S.

5. Hinka B. I. Lexikologie der deutschen Sprache: Vorlesungen und Seminare. Навчальний посібник для студентів-германістів. Тернопіль: Редакційно-видавничий відділ Тернопільського національного педагогічного університету імені В.Гнатюка, 2005. 220 с.

6. Ladtschenko M. M. Halbsuffixe der Substantive zum Ausdruck der negativen Eigenschaften der Menschen in der deutschen Umgangssprache. IV Таврійські філологічні читання: Матеріали Всеукраїнської науковопрактичної конференції: м. Херсон, 28-29 вересня 2018 р. Херсон: Херсонський державний університет, 2018. С. 99 -103.

7. Stepanova M. D., Černyševa I.I. Lexikologie der deutschen Gegenwartssprache. M.: Hochschule, 1986. 247 S.

8. Wahrig G. Grammatik der deutschen Sprache, Gütersloh / München : Bertelsmann Lexikon Verlag, 1999. - 702 S.

9. Девкин В. Д. Немецко-русский словарь разговорной лексики. М.: Русский язык, 1994. 768 с.

10.Кульчицький В. Класифікація похідних слів сучасної німецької мови на основі семантичних категорій. Гуманітарна освіта в технічних вищих навчальних закладах. 2017. № 36. С. 24-29.

11.Ладченко М. М. Словотвірні особливості іменників у німецькій розмовній мові. Modern philology: relevant issues and prospects of research: Conference proceedings (October 20-21, 2017). Lublin: Izdevnieciba «Baltija Publishing», 2017. C. $105-109$. 
12.Ладченко М. М. До проблеми збагачення словникового складу німецької розмовної мови. Таврійські філологічні наукові читання: матеріали міжнародної наук.-практ. Конф. (Київ, 27-28 січня 2017 р.) Київ: Таврійський національний університет імені В. І. Вернадського, 2017. С. $99-103$.

13.Мюллер В. Великий німецько-український словник. К.: Чумацький шлях, 2005. $792 \mathrm{c}$.

14.Перестюк Т. Аугментативні похідні із зоосемічним компонентом у німецькій мові. URL: https:// old.lingua.lnu.edu.ua/ Foreign_Philology _120/articles/11\% 20 perestiuk\%20vypravleno\%20formatted.pdf (дата звернення 18. 06. 2020).

15.Ходаковська Н.Г. Семантичний та прагматичний аспекти стилістично маркованих похідних іменників сучасної німецької мови. URL: https:// mydisser.com/ua/catalog /view /312/771/22044.html (дата звернення 15. 10. 2019).

УДК $811.111+81^{\prime} 42$

DOI: $10.24144 / 2617-3921.2020 .18 .80-90$

Антоніна Марковська кандидат філологічних наук, дочент кафедри іноземних мов Миколаївський національний аграрний університет, orcid.org/0000-0003-1598-7517 м. Миколаїв, Україна $+38(066) 4907450$ markovska@mnau.edu.ua Ольга Саламатіна кандидат філологічних наук, дочент кафедри іноземних мов Миколаӥвський національний аграрний університет, orcid.org/0000-0002-1457-2822 м. Миколаїв, Україна $+38(066) 3369027$ salamatina@mnau.edu.ua

\section{Functional features of the modern foreign publicistic interview}

Анотація. Стаття присвячена розкриттю понять «функиіональна прагмалінгвістика», «функиіональний стиль» та виділенню їхніх важливих рис. Виявлено, щзо міждисциплінарний підхід до тексту як до інструменту та продукту пізнавально-комунікативної діяльності, що відбувається у проиесі відображення реальності суб'єктами пізнання, стає все більш актуальним. 